\title{
Tranexamic Acid versus Carbetocin for Reduction of Blood Loss during Abdominal Myomectomy: A Randomized Clinical Trial
}

\author{
Mariam Lotfy ${ }^{1}$, Zakia M Ibrahim ${ }^{1}$, Ahmed M Abbas ${ }^{2 *}$, Sherehan M Alkeplawy ${ }^{1}$ and Khaled A Atwa ${ }^{1}$ \\ ${ }^{1}$ Department of Obstetrics and Gynaecology, Faculty of Medicine, Suez Canal University, Egypt \\ ${ }^{2}$ Department of Obstetrics and Gynaecology, Faculty of Medicine, Assiut University, Egypt
}

*Corresponding author: Ahmed M Abbas, Department of Obstetrics and Gynaecology, Assiut University, Women Health Hospital, Egypt.
Received Date: April 09, 2020

Published Date: April 27, 2020

\section{Abstract}

Introduction: Uterine fibroids are benign tumours of the uterus. They represent the most common benign tumour of the female genital tract during reproductive period. The aim of this study was to decrease blood loss during myomectomy using carbetocin in comparison with tranexamic acid.

Material and Methods: In this randomized clinical trial, 132 patients with uterine fibroids were enrolled for our study at Gynaecology outpatient clinic, Suez Canal University Hospitals, from May 2016 to May 2018. Patients were assessed by full history, clinical examination, transvaginal ultrasound and laboratory investigations. After patients' counselling and consent, they were randomly assigned into 2 groups (66 patients each); the first group received $30 \mathrm{ml}$ of sodium chloride with added 50mg tranexamic acid, while the second group received $30 \mathrm{ml}$ of sodium chloride with added $100 \mathrm{mg}$ Carbetocin. Both drugs were delivered at the time of skin incision by intravenous infusion. The amount of blood loss was estimated intra-operatively and post-operatively and the collected data were statistically analysed.

Results: Total blood loss was significantly lower in the carbetocin group $(399.27 \pm 28.94 \mathrm{ml})$ than the tranexamic acid group $(535.15 \pm 80.30 \mathrm{ml})$ $(\mathrm{p}<0.001)$. Intra-operative blood loss was significantly lower in the carbetocin group $(371.39 \pm 27.54 \mathrm{ml})$ than the tranexamic acid group $(478.48$ $\pm 60.4 \mathrm{ml})(\mathrm{p}<0.001)$. Post-operative blood loss was significantly lower in the carbetocin group $(27.88 \pm 32.32 \mathrm{ml})$ than the tranexamic acid group $(56.67 \pm 53.13 \mathrm{ml})(\mathrm{p} 0.001)$.

Conclusion: Carbetocin is more effective than tranexamic acid on reduction of blood loss during abdominal myomectomy.

Keywords: Fibroids; Myomectomy; Blood loss; Tranexamic acid; Carbetocin

\section{Introduction}

Uterine leiomyomas represent the most common benign tumours encountered in women, originating from myometrium smooth muscle cells. These tumours are estrogen dependent and grow during the reproductive period with incidence of approximately $70 \%$ in the general population [1]. Approximately $20-40 \%$ of women with fibroids experience significant symptoms and consult gynecologic care. However, their true prevalence is probably under-estimated [2].

The standard approach for treating leiomyoma is hysterectomy for women who do not want to have more children and myomectomy for those who want to preserve fertility [3]. Bleeding during myomectomy is one of the major complications which can result in significant morbidity and mortality. Despite advances in reducing excessive haemorrhage during the procedure, it still remains a major challenge for gynecologic surgeons [4].

Several interventions have been developed to control bleeding during this operation such as dissection and embolization of uterine artery, use of mechanical tourniquets, use of uterotonic medications such as oxytocin, Carbetocin, ergometrine, misoprostol and manipulation of the coagulation cascade with antifibrinolytic treatment, especially aprotinin, tranexamic acid, epsilonaminocaproic acid, desmopressin and recombinant factor VIIa [5]. 
Tranexamic acid (TA), a synthetic lysine derivative with antifibrinolytic activity has been used since the 1960s in a variety of clinical settings where anti-fibrinolytic therapy is appropriate. It acts as an anti-fibrinolytic through the reversible blockade of lysine-binding sites on plasminogen molecules. It is an inhibitor of fibrinolysis. It has been routinely used for many years to reduce haemorrhage during and after surgical procedures. It has been shown to be very useful for reducing blood loss and blood transfusions [6].

Carbetocin is a synthetic long-acting oxytocin analogue. Its intravenous half-life is 85 to $100 \mathrm{~min}$ which is 10 times longer than that of oxytocin. It has a rapid onset and long- lasting action. Carbetocin and uterine oxytocin receptors in the uterus caused rhythmic contraction, which can increase the frequency of existing contractions as well as uterine tone. During surgery, the uterine smooth muscles were made to contract, so that the tumour protrudes from the uterine surface and the level of the tumour cavity would be easy to find and peel [7].

There are no enough studies that compare the efficacy and safety of using intravenous tranexamic acid and intravenous Carbetocin for reduction of blood loss during myomectomy, therefore, this study aims to assess and compare between them for their ability to reduce blood loss during myomectomy.

\section{Materials and Methods}

This randomized clinical trial was carried out in the obstetrics and gynaecology department of Suez Canal University Hospital and included 132 female patients with uterine fibroids that necessitated abdominal myomectomy in the period from May 2016 to May 2018.

Inclusion criteria included patients with age ranging from 18 to 50 years with documented uterine fibroids on pelvic imaging (pelvic ultrasound or MRI) within last 12 months, patients complaining of abnormal vaginal bleeding, chronic pelvic pain, pressure symptoms or reproductive disorders with pre-operative haemoglobin> 8g/ dl. Exclusion criteria included post-menopausal women together with patients previously treated with Depo-Lupron, DepoProvera or oral contraceptive pills, patients with known bleeding/ clotting disorders, active liver, kidney or cardiovascular disease or receiving anticoagulant, NSAIDs or antiplatelet, previous history of gynecological malignancy, previous abdominal myomectomy or venous thromboembolism.

After approval to participate in the study by providing informed written consent, patients had been allocated to either group using Simple randomization by a randomization table created by a computer software program. A full history was taken included personal, menstrual, obstetrics, contraceptive, past and surgical histories. All patients had full clinical examination included general, abdominal and vaginal examinations. Laboratory investigations were done including haemoglobin, hematocrit, platelet count, prothrombin time and partial thromboplastin time. An abdominal or transvaginal ultrasound was done to assess the size, number, and location of myomas.
At the time of skin incision, the patients in the first group $(n=66)$ received $30 \mathrm{ml}$ of sodium chloride with added 500mg tranexamic acid (Kapron $500 \mathrm{mg}$ ampoule, Amoun pharmaceuticals) by intravenous infusion while cases in $2^{\text {nd }}$ group $(n=66)$ received $30 \mathrm{ml}$ of sodium chloride with added $100 \mathrm{mcg}$ Carbetocin (Pabal $100 \mathrm{mcg}$ ampoule, Ferring Pharmaceuticals) also by intravenous infusion. The blood loss was assessed from the start of the operation till skin closure and also post-operative till the second post-operative day or till the removal of the drain. The weight of the dry surgical swabs (30 g for each $30 * 30 \mathrm{~cm}$ abdominal swabs) was measured before use and after being wet or soaked by blood. A highly accurate digital balance was used to measure the weight in grams. The weight difference was translated into the blood loss considering that $1 \mathrm{~g}$ is equal to $1 \mathrm{ml} \mathrm{bl}$. The amount of intraoperative blood loss $(\mathrm{ml})=$ (the weight of used towels-the weight of towels prior to surgery) + blood in suction apparatus. The amount of postoperative blood loss was assessed by the insertion of intraperitoneal tube drain and the calculation of amount of blood in the drain till the drain removed.

Blood transfusion was done if blood loss was more than 2,000 cc and/or the hemoglobin after $6 \mathrm{~h}$ was less than $7 \mathrm{gm}$.

Sample size: A sequential sample size calculation was used

$$
n=2\left[\frac{\left(Z_{\alpha / 2}+Z_{\beta}\right) * \sigma}{\mu_{1}-\mu_{2}}\right]^{2}
$$

Where:

$\mathrm{n}=$ required sample size,

$\mathrm{Z}_{\alpha / 2}=1.96$ (The critical value that divides the central $95 \%$ of the $\mathrm{Z}$ distribution from the $5 \%$ in the tail)

$\mathrm{Z}_{\beta}=0.84$ (The critical value that separates the lower $20 \%$ of the $\mathrm{Z}$ distribution from the upper $80 \%$ )

$\sigma$ is the estimate of the standard deviation in the study group

$\mu_{1}=$ mean in the group $1 \mu_{2}=$ mean in the group 2 [9]

$10 \%$ drop out was calculated. This gave a total number of 132 patients divided into two groups.

\section{Outcome Measures}

\section{Primary outcome measures}

- Estimated intra-operative blood loss [Time Frame: Intraoperative]

- Estimate of blood loss occurring during the surgical procedure as determined by anaesthesia staff and documented by anaesthesia, nursing and surgical staff as per hospital protocol.

\section{Secondary outcome measures}

- $\quad$ Length of inpatient hospitalization [Time Frame: Number of days the patient is hospitalized post-operatively, an expected average of 3 days and a maximum of 90 days post-operatively ] 
- $\quad$ Post-operative blood transfusion [Time Frame: From time of surgery completion through discharge from hospital, an expected average period of 3 days ]

\section{Ethical approval}

The study was approved from the ethical committee on 17/04/2016 with a research number 3026. The adopted procedures were in accordance with the ethical standards of the ethical committee on human experimentation and with the Helsinki Declaration. Clinical trial registration number: PACTR201908793583382.

\section{Statistical Analysis}

Data was statistically described in terms of mean and standard deviation, frequencies (number of cases) and percentages when appropriate. $P$ values less than 0.05 were considered statistically significant. All statistical calculations were done using computer program SPSS (Statistical Package for the Social Science; SPSS Inc., Chicago, IL, USA) release 22 for Microsoft Windows. Parametric tests were used in variables with normal distribution. Non-normally distributed data was tested using non- parametric tests.

\section{Results}

One hundred and fifty (150) patients were evaluated for eligibility to the study criteria. Of the total, eight women did not meet the criteria, and 10 declined participation. The study included 132 patients randomized into 66 for each group. The CONSORT flow diagram of the study is shown in Figure 1.

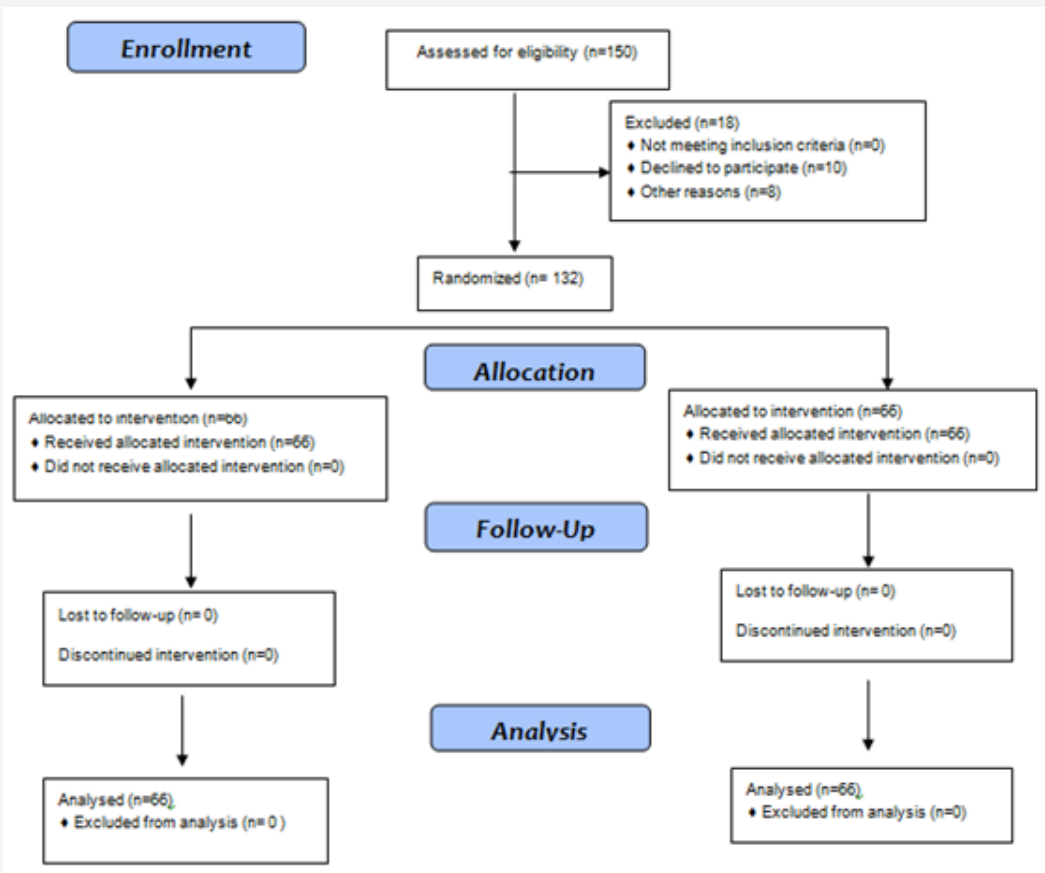

Figure 1: Flowchart of the study participants.

Demographically, the mean of age in Group I was $38.03 \pm 5.04$ years while it was $36.97 \pm 4.16$ years in Group II with no statistically significant difference. There was no statistical significant difference between both groups regarding the anthropometric measures (height, weight and BMI). One hundred patients (75.8\%) were married; however, about one quarter of them (34 patients $26.5 \%$ )

Table 1: Demographic data of the patients. had no parity. On the other hand, 54 patients (40.9\%) in both groups had no previous abdominal operations. Moreover, there was no statistically significant difference between both groups regarding demographic data. Meanwhile, there was no statically significant difference between both groups in size of largest myoma, myoma stage or number of myomas (Table 1).

\begin{tabular}{|c|c|c|c|c|}
\hline \multicolumn{2}{|c|}{ Variable } & Group $1(\mathrm{~N}=66)$ & Group $2(\mathrm{~N}=66)$ & P value \\
\hline \multicolumn{2}{|c|}{ Age (Years) Mean \pm SD } & $38.03 \pm 5.04$ & $36.97 \pm 4.16$ & 0.19 \\
\hline \multicolumn{2}{|c|}{ BMI $\left(\mathrm{kg} / \mathrm{m}^{2}\right)$ Mean $\pm \mathrm{SD}$} & $27.86 \pm 3.24$ & $28.03 \pm 3.17$ & 0.761 \\
\hline \multirow{2}{*}{$\begin{array}{l}\text { Parity } \\
\text { No (\%) }\end{array}$} & NPNG & $14(21.21 \%)$ & $20(30.3 \%)$ & \multirow{2}{*}{0.232} \\
\hline & Multipara & $52(78.79 \%)$ & $46(69.7 \%)$ & \\
\hline \multirow{3}{*}{$\begin{array}{c}\text { Number of myomas } \\
\text { No (\%) }\end{array}$} & 1 Myoma & $4(6.06 \%)$ & $4(6.06 \%)$ & \multirow{3}{*}{0.523} \\
\hline & 2-4 Myomas & $44(66.67 \%)$ & $38(57.58 \%)$ & \\
\hline & $\geq 5$ Myomas & $18(27.27 \%)$ & $24(36.36 \%)$ & \\
\hline \multirow{2}{*}{$\begin{array}{c}\text { Size of largest myoma } \\
\text { No (\%) }\end{array}$} & $<5 \mathrm{~cm}$ & $32(48.48 \%)$ & $30(45.45 \%)$ & \multirow{2}{*}{0.727} \\
\hline & $\geq 5 \mathrm{~cm}$ & $34(51.52 \%)$ & $36(54.55 \%)$ & \\
\hline
\end{tabular}




\begin{tabular}{|c|c|c|c|c|}
\hline \multirow{4}{*}{$\begin{array}{c}\text { Myoma stage } \\
\text { No (\%) }\end{array}$} & 3 & $18(27.27 \%)$ & $14(21.21 \%)$ & \multirow{4}{*}{0.825} \\
\hline & 4 & $14(21.21 \%)$ & $14(21.21 \%)$ & \\
\hline & 5 & $16(24.24 \%)$ & $16(24.24 \%)$ & \\
\hline & 6 & $18(27.27 \%)$ & $22(33.33 \%)$ & \\
\hline
\end{tabular}

Regarding blood loss, it was found that Group II had significantly lower intra-operative, post-operative and total blood loss than Group I ( $p<0.001$ for each). Pre-operatively, there was no statistically significant difference between both groups in terms

Table 2: Evaluation of the study outcomes among both groups.

\begin{tabular}{|c|c|c|c|c|}
\hline \multicolumn{2}{|c|}{ Parameter } & Group I $(\mathrm{N}=66)$ & Group II(N=66) & $\mathrm{p}$ value \\
\hline \multicolumn{2}{|c|}{ Total blood loss (ml) Mean \pm SD } & $535.15 \pm 80.30$ & $399.27 \pm 28.94$ & $<0.001$ \\
\hline \multicolumn{2}{|c|}{ Intraoperative blood loss(ml) Mean \pm SD } & $478.48 \pm 60.40$ & $371.39 \pm 27.54$ & $<0.001$ \\
\hline \multicolumn{2}{|c|}{ Postoperative blood loss(ml) Mean \pm SD } & $56.67 \pm 53.13$ & $27.88 \pm 32.32$ & $<0.001$ \\
\hline \multirow{3}{*}{$\begin{array}{c}\text { Hematocrit (\%) } \\
\text { Mean } \pm \text { SD }\end{array}$} & Preoperative & $33.53 \pm 2.39$ & $33.80 \pm 2.47$ & 0.524 \\
\hline & 6 hours postoperative & $31.68 \pm 2.35$ & $32.61 \pm 2.69$ & 0.036 \\
\hline & 72 hours postoperative & $30.71 \pm 2.60$ & $31.91 \pm 2.69$ & 0.01 \\
\hline \multirow{3}{*}{$\begin{array}{c}\text { Hemoglobin } \\
\text { (g/dl)Mean } \pm \text { SD }\end{array}$} & Preoperative & $11.19 \pm 0.98$ & $11.41 \pm 1.01$ & 0.206 \\
\hline & 6 hours postoperative & $10.27 \pm 0.99$ & $10.95 \pm 1.00$ & $<0.001^{*}$ \\
\hline & 72 hours postoperative & $9.95 \pm 1.0$ & $10.63 \pm 1.01$ & $<0.001^{*}$ \\
\hline
\end{tabular}

*Statistically significant difference

There was no statically significant difference between both groups in terms of the Duration of surgery. Patients in Group II had statistically significant lower hospital stay duration $(2.42$ \pm 0.5 days) than Group I ( $2.64 \pm 0.48$ days) ( $\mathrm{p}=0.015$ ) (Table 3$)$.

of hemoglobin and hematocrit levels. However, it was found that hemoglobin level was significantly higher in Group II; 6 hours and 72 hours after operation compared to Group I ( $p<0.001)$ while hematocrit levels were not changed significantly (Table 2).
Blood transfusion wasn't required at all in our studied population. Regarding the side effects, Group I was associated with more side effects than Group II (p 0.011) (Table 3).

Table 3: Operation related parameters among both groups.

\begin{tabular}{|c|c|c|c|c|}
\hline \multicolumn{2}{|c|}{ Parameter } & Group I (N=66) & Group II (N=66) & p value \\
\hline \multirow{2}{*}{ Duration of surgery (Hours) Mean \pm SD } & $1.67 \pm 0.33$ & $1.67 \pm 0.28$ & 1.00 \\
\hline \multirow{2}{*}{ Hospital stay (Days) Mean \pm SD } & $2.64 \pm 0.48$ & $2.42 \pm 0.5$ & $0.011^{*}$ \\
\cline { 1 - 4 } Side effects & Nausea & $8(12.1 \%)$ & $4(6.1 \%)$ & \multirow{2}{*}{$0.001^{*}$} \\
\cline { 2 - 5 } & Vomiting & $6(9.1 \%)$ & $0(0.0 \%)$ & \\
\cline { 2 - 5 } & Total & $14(21.21 \%)$ & $4(6.06 \%)$ & \\
\hline
\end{tabular}

*Statistically significant difference

\section{Discussion}

In the present study, the amount of blood loss was significantly higher in Group I as compared to Group II (intra-operative and post-operative) ( $p<0.001)$. This would be explained as the fibroid itself has poor vascularity but the surrounding myometrium has a rich network of blood vessels. The fibroid also causes mechanical obstruction to the venous drainage of the myometrium and endometrium with congestion and dilatation of the surrounding venous plexuses [10]. Enucleation of the intramural fibroids from the pseudo-capsule can result in brisk bleeding from the adjoining blood vessels. The dead space created by the enucleation of fibroids is a potential site for accumulation of haematomas [11]. Agostini and others, 2005 used oxytocin to decrease blood loss during myomectomy and concluded that the benefits of using oxytocin to prevent haemorrhage during myomectomy are limited [12]. Contradictory results were reported by Wang and colleagues, 
reduced total blood loss, yet haemoglobin decline and transfusion requirements were noted [17]. Additional studies confirmed the advantageous effect of tranexamic acid in reducing blood loss in patients undergoing open myomectomy $[9,18]$.

Strengths of this study included the recruitment of two matched groups allocated for two regimens for reducing blood loss during myomectomy. Also considering the estimation of blood loss as our primary outcome measure is significant. Larger sample sizes would be more informative. We used an accurate method for estimation of blood loss that depends on the amount of suctioned blood as well as the weight difference of the used towels. Besides, there are no enough researches in the literature comparing tranexamic acid with carbetocin in this surgery, making this data of great importance.

\section{Conclusion}

Carbetocin is more effective than tranexamic acid on reduction of blood loss during abdominal myomectomy.

\section{Acknowledgement}

None.

\section{Conflict of Interest}

No conflict of interest to be declared.

\section{References}

1. Drayer SM, Catherino WH (2015) Prevalence, morbidity, and current medical management of uterine leiomyomas. Int J Gyn Obs 131(2): 117122.

2. Eltoukhi HM, Modi MN, Weston M, Armstrong AY, Stewart EA (2014) The health disparities of uterine fibroid tumors for African American women: a public health issue. Am J Obstet Gynecol 210(3): 194-199.

3. Marret H, Fritel X, Ouldamer L, Bendifallah S, Luc Brun J, et al. (2012) Therapeutic management of uterine fibroid tumors: updated French guidelines. Eur J Obstet Gynecol Reprod Biol 165(2): 165-164.

4. Donnez J, Dolmans MD (2016) Uterine fibroid management: from the present to the future. Hum Reprod Update 22(6): 665-686.

5. Duhan N (2011) Current and emerging treatments for uterine myoma an update. Int J Womens Health, 3:231-241.
6. Nishida T, Kinoshita T, Yamakawa K (2017) Tranexamic acid and traumainduced coagulopathy. J Intensive Care 5: 5.

7. Farouk H, Shady N (2017) Intravenous Carbetocin to decrease blood loss during open myomectomy: a randomized placebo-controlled study. IJRCOG 7: 27.

8. Buderer NM (1996) Statistical methodology: I. Incorporating the prevalence of disease into the sample size calculation for sensitivity and specificity. Acad Emerg Med 3(9): 895-900.

9. Caglar GS, Tasci Y, Kayikcioglu F, Haberal A (2008) Intravenous tranexamic acid use in myomectomy: A prospective randomized double-blind placebo controlled study. European Journal of Obstetrics \& Gynecology and Reproductive Biology 137(2): 227-231.

10. Huyck KL, Panhuysen CM, Cuenco KT, Zhang J, Goldhammer H, et al. (2008) The impact of race as a risk factor for symptom severity and age at diagnosis of uterine leiomyomata among affected sisters. Am J Obstet Gynecol 198(2): 168.

11. Mukhopadhaya N, De Silva C, Manyonda IT (2008) Conventional myomectomy. Best Pract Res Clin Obstet Gynaecol 22(4): 677-705.

12. Agostini A, Ronda I, Franchi F, Bretelle F, Roger V, et al. (2005) Oxytocin during myomectomy: a randomized study. Eur J Obstet Gynecol Reprod Biol 118(2): 235-238.

13. Wang CJ, Lee CY, Yuen LT, Kay N, Han CM, et al. (2007) Oxytocin infusion in laparoscopic myomectomy may decrease operative blood loss. J Minim Invasive Gynecol 14(2): 184-188.

14. Yang M, Chengyong W, Xuezhen W, Mei L, Liping, L (2012) Using carbetocin to Prevent hemorrhage in laparoscopic myomectomy AJPPh 6: 2023-2026.

15. Gad Allah S, Wali A, Mostafa S (2015) Hemostatic effect and postoperative benefits of intramyometrial carbetocin injection during myomectomy. EBWHJ 5(4): 185-189.

16. Sallam H, Shady N (2018) Intravenous Carbetocin to decrease blood loss during open myomectomy: a randomized placebo-controlled study. IJRCOG 7(1): 27-32.

17. Wang D, Wang L, Wang Y, Lin X (2018) The efficiency and safety of tranexamic acid for reducing blood loss in open myomectomy. A metaanalysis of randomized controlled trials. Medicine (Baltimore) 97(4): e9793.

18. Shaaban MM, Ahmed MR, Farhan RE, Dardeer HH (2015) Efficacy of Tranexamic Acid on Myomectomy-Associated Blood Loss in Patients With Multiple Myomas: A Randomized Controlled Clinical Trial Rep Sci 23(7): 908-912. 